\title{
Clinical features of anti-neutrophil cytoplasmic antibody-associated systemic vasculitis in French children
}

\author{
AS Sacri ${ }^{*}$, B Ranchin ${ }^{2}$, B Florkin ${ }^{3}$, H See ${ }^{4}$, T Ulinski ${ }^{5}$, H Flodrops ${ }^{6}$, S Decramer ${ }^{7}$, R Salomon ${ }^{8}$, P Quartier ${ }^{3}$, \\ J Harambat ${ }^{1}$
}

From 18th Pediatric Rheumatology European Society (PReS) Congress

Bruges, Belgium. 14-18 September 2011

\section{Background}

Anti-neutrophil cytoplasmic antibody (ANCA)-associated vasculitis is mainly reported in adults. Data in children is scarce. The current study aimed to describe the clinical features of the disease at diagnosis and the long-term outcomes in pediatric patients with ANCAassociated vasculitis.

\section{Methods}

This retrospective study was conducted in 9 French Hospitals (mainly pediatric nephrology units) and includes patients diagnosed during the past 25 years. Wegener's granulomatosis (WG) and microscopic polyangiitis (MPA) were included, but not Churg-Strauss syndrome.

\section{Results}

Forty-seven children were included, 15 (32\%) with WG and $32(68 \%)$ with MPA, 77\% children were pANCA $+/$ MPO. Female predominated (85\%), the median age at diagnosis was 10 years (2-16), and average time to diagnosis was 8 months (0-58). 53\% children presented with fever, $77 \%$ with deterioration of general condition. $91 \%$ had renal involvement. Among them $91 \%$ had proteinuria, $44 \%$ had hypertension, $79 \%$ had renal failure of whom one third presented with end-stage renal disease (ESRD), 22\% had gross hematuria and $82 \%$ microscopic hematuria. Half the patients showed pulmonary involvement (alveolar hemorrhage for $77 \%$ and nodules for $18 \%$ ). $28 \%$ presented with upper airways involvement, $38 \%$ with cutaneous lesions (67\% purpura), and 19\% with arthritis. Few had digestive, ophthalmic or CNS involvement. After an average follow-up of 5 years $(2 \mathrm{~m}$ $24 y), 3$ patients $(6 \%)$ died. $60 \%$ were considered in remission (partial or total) after induction treatment and $77 \%$ at last follow-up. 33\% of children with initial renal involvement developed chronic kidney disease, half of them progressed to ESRD. 43\% needed dialysis and 29\% underwent a renal transplantation.

\section{Conclusion}

Clinical features and outcome in children with ANCAvasculitis are close to the findings in adults but they are characterized by delayed diagnosis and female predominance. Although the cases may be selected, renal involvement appears as a major prognostic factor of the disease.

\section{Author details \\ 'Department of Pediatric Nephrology, CHU Pellegrin, Bordeaux, France. ${ }^{2}$ Department of Pediatric Nephrology, HFME, Lyon, France. ${ }^{3}$ Department of Pediatric Rhumatolgy, Necker Enfants Malades, Paris, France. ${ }^{4}$ Department of Pediatric Nephrology, CHU Robert Debré, Paris, France. ${ }^{5}$ Department of Pediatric Nephrology, CHU Armand Trousseau, Paris, France. ${ }^{6}$ Department of Pediatric Nephrology, CHR Réunion, France. 'Department of Pediatric Nephrology, CHU Toulouse, France. ${ }^{8}$ Department of Pediatric Nephrology, Necker Enfants Malades, Paris, France.}

Published: 14 September 2011

doi:10.1186/1546-0096-9-S1-P88

Cite this article as: Sacri et al:: Clinical features of anti-neutrophil cytoplasmic antibody-associated systemic vasculitis in French children. Pediatric Rheumatology 2011 9(Suppl 1):P88.

* Correspondence: annesylvia.sacri@yahoo.fr

'Department of Pediatric Nephrology, CHU Pellegrin, Bordeaux, France

Full list of author information is available at the end of the article

(c) 2011 Sacri et al; licensee BioMed Central Ltd. This is an open access article distributed under the terms of the Creative Commons 